\title{
Interpreting iron studies
}

\author{
Alison U Kelly specialty registrar in chemical pathology ${ }^{1}$, Stephen T McSorley clinical research \\ fellow $^{2}$, Prinesh Patel general practitioner ${ }^{3}$, Dinesh Talwar consultant clinical scientist ${ }^{1}$ \\ ${ }^{1}$ Department of Biochemistry, Glasgow Royal Infirmary, Glasgow, UK; ${ }^{2}$ Academic Unit of Surgery, School of Medicine, University of Glasgow, \\ Glasgow Royal Infirmary, Glasgow, UK; ${ }^{3}$ Alva Medical Practice, Alva, Stirlingshire, UK
}

A 63 year old woman visits her doctor with a three month history of fatigue and generalised joint pains. Her medical history is unremarkable and she reports no recent stress, infection, or weight loss. There are no abnormalities on clinical examination. Haemoglobin, creatinine, and electrolytes, liver enzymes, glucose, inflammatory markers, and thyroid function tests are normal. Ferritin, iron, transferrin, and transferrin saturation are also requested.

This article discusses some situations in which ferritin and iron studies might be helpful and how to avoid common pitfalls in their interpretation.

\section{What are the next investigations?}

The doctor in this case requested iron studies to investigate the possibility of iron overload and to screen for haemochromatosis. Iron studies are also commonly indicated in clinical practice to investigate iron deficiency, or to monitor response to treatment for these conditions (box 1).

Conventional laboratory tests of iron status are often referred to as "iron studies." They include tests for serum ferritin, iron, transferrin, or total iron binding capacity (TIBC), and transferrin saturation.

Iron is a key component of haemoglobin in red blood cells, myoglobin in muscle, and many metalloproteins and enzymes. It is essential for uptake of oxygen and its delivery to tissues, utilisation of oxygen by muscle cells, and mitochondrial energy production. ${ }^{3}$ Normal iron metabolism and regulation is outlined in Figure $1 \Downarrow$. The adult male body contains 3-5 g of iron. Less than $0.1 \%$ of total body iron stores circulate in plasma. Dietary $\mathrm{Fe}^{3+}$ is reduced to $\mathrm{Fe}^{2+}$ and transported into the enterocyte by the divalent metal transporter DMT1. Iron is exported across the basolateral membrane via the iron export protein ferroportin 1 or stored as ferritin. Transferrin bound iron binds to transferrin receptor 1 (TFR1) and is taken up into the cell via receptor mediated endocytosis. Expression of TFR1 is regulated locally by the iron demands of the cell, via binding of iron regulatory proteins. Old or damaged erythrocytes are removed from the circulation by splenic macrophages. Iron is removed from haem by haem oxygenase 1 , and either stored as ferritin or released into the circulation.

Regulation of iron release at a systemic level is mediated by the peptide hormone hepcidin (produced predominantly by hepatocytes) and has an inhibitory effect on iron release from cells and dietary iron absorption. Expression is controlled by complex signalling pathways. ${ }^{1}$

\section{What is included in iron studies?}

Ferritin-is the intracellular storage form of iron. A very small amount is found in serum. In inflammation, liver disease, and malignancy, ferritin levels can rise because ferritin is an acute phase protein. ${ }^{4}$ In these patients, ferritin can appear either falsely high or normal, when in reality stores are low.

Serum iron-refers to ferric ions $\left(\mathrm{Fe}^{3+}\right)$ bound to serum transferrin. Serum iron concentration is highly variable and is affected by dietary iron intake, inflammation, and infection. ${ }^{5}$

Transferrin-is the principal iron transport protein in plasma. It increases in iron deficiency to maximise utilisation of available iron. ${ }^{4}$ Total iron binding capacity is an alternative test to transferrin. TIBC reflects the availability of iron binding sites on transferrin. Values increase in iron deficiency and decrease in iron overload. Some laboratories measure unsaturated iron binding capacity (UIBC) and calculate TIBC by adding serum iron to UIBC.

Transferrin saturation - is calculated from serum iron and either TIBC or transferrin measurements. Typically, transferrin is $30 \%$ saturated with iron. ${ }^{5}$ Transferrin saturation rises in iron overload and falls in iron deficiency, but does not quantitatively reflect iron stores. ${ }^{1}$ A rise in serum iron due to dietary iron intake can cause raised transferrin saturation. 


\section{What you need to know \\ -Iron overload typically results in a high ferritin and transferrin saturation \\ -Iron deficiency is best assessed using serum ferritin, which is low in the absence of inflammation \\ -Ferritin levels can be elevated by inflammatory processes and can mask iron deficiency}

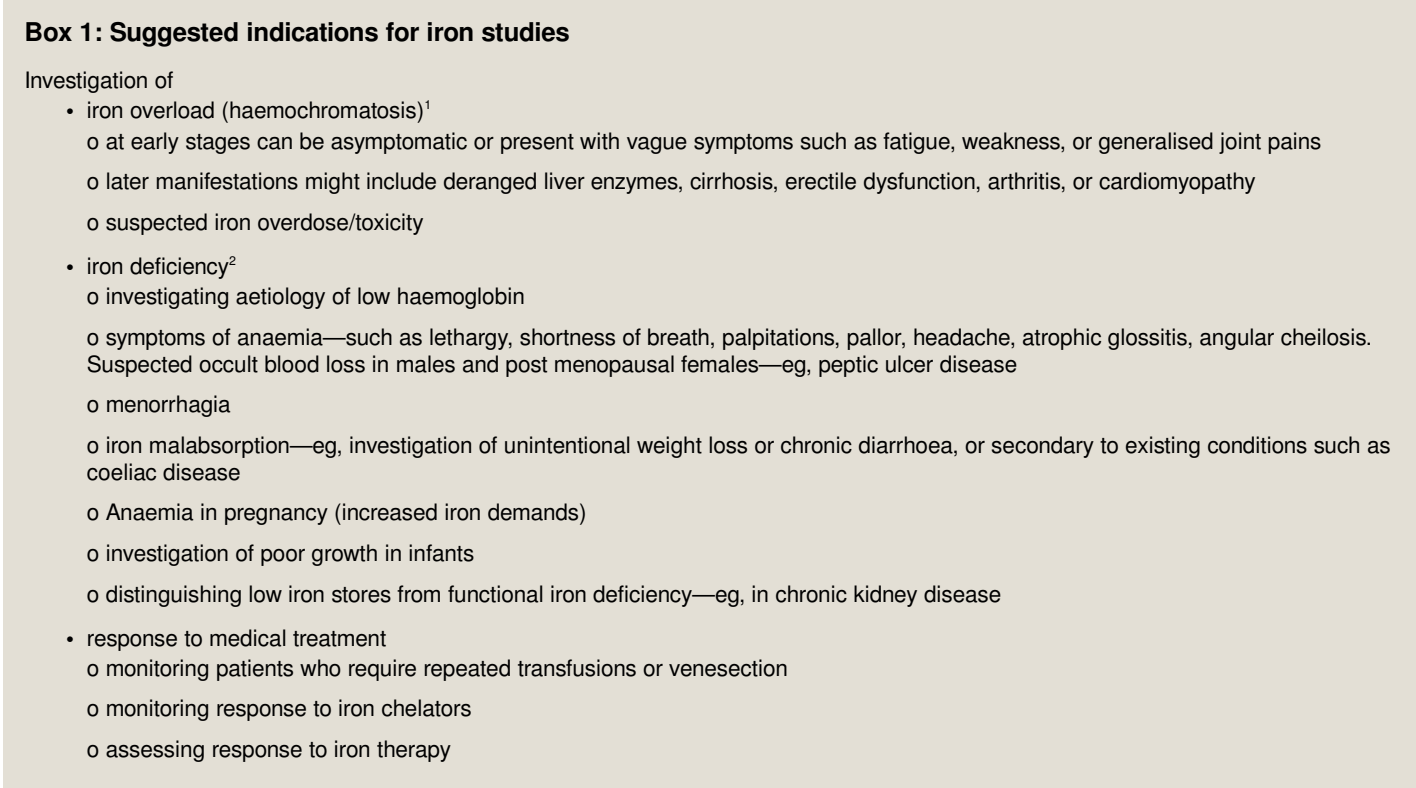

\section{Interpretation}

Interpretation of iron studies can be challenging because the difficulties listed above affect almost all markers of iron status. Nevertheless, iron studies play an important role in clinical assessment (table $1 \Downarrow$ ). Reference intervals are quoted; however, these can vary by laboratory and must be confirmed locally.

\section{Iron overload}

Testing for iron overload (increased total body iron stores with or without organ dysfunction) can be triggered by clinical features such as those listed in box 1. Primary iron overload includes inherited mutations in iron regulatory genes (causing iron loading syndromes such as haemochromatosis). Secondary iron overload is associated with other conditions or iatrogenic factors (box 2).

Hereditary haemochromatosis (an autosomal recessive genetic condition caused by mutation of the HFE gene) is the most common inherited cause of iron overload. Homozygosity for the $\mathrm{C} 282 \mathrm{Y}$ polymorphism affects 1 in 200 people of northern European descent and accounts for more than $80 \%$ of clinically recognised cases. Clinical penetrance varies widely (1\%-28\% of C282Y homozygotes in population studies). ${ }^{7}$ In an unselected population, raised serum ferritin ( $>200 \mu \mathrm{g} / \mathrm{L}$ for premenopausal women or $>300 \mu \mathrm{g} / \mathrm{L}$ for men and postmenopausal women) and transferrin saturation $>50 \%$ diagnosed $\mathrm{C} 282 \mathrm{Y}$ homozygosity with a sensitivity of $90 \%$ in men and $75 \%$ in women. ${ }^{8}$ An approach to hyperferritinaemia has previously been discussed. ${ }^{6}$ Specialist techniques for assessing iron overload include liver biopsy, magnetic resonance imaging, and superconducting quantum interference device susceptometry, a non-invasive technique that measures the amount of in vivo magnetisation caused by hepatic iron. ${ }^{1}$ Indications for these tests can include marked hyperferritinaemia $(>1000 \mu \mathrm{g} / \mathrm{L})$ or further assessment when the diagnosis of iron overload is in doubt. They are not widely available and are usually requested by specialists.

\section{Tips on requests and interpretation}

- Request serum ferritin and transferrin saturation together to assess for iron overload, alongside haemoglobin to identify anaemia and aid treatment decisions (eg, venesection).

- If elevated transferrin saturation is the only biochemical abnormality or the result is borderline, repeat the test on a fasting sample to eliminate a rise caused by dietary iron.

- If transferrin saturation is persistently raised, offer HFE gene analysis with pre-test counselling.

- In C282Y homozygotes, transferrin saturation is the first biochemical parameter to rise. Serum ferritin might be normal in the early stages of the disease, however some patients later develop clinically significant iron overload ${ }^{7}$ (organ dysfunction with or without symptoms). Annual monitoring of serum ferritin is proposed in established guidelines. ${ }^{1}$ In the absence of local defined protocols, consider referral for further assessment if hyperferritinaemia develops or ferritin is progressively rising.

- Ingestion of therapeutic iron (including iron containing multivitamins) can raise transferrin saturation to levels reaching $100 \%,{ }^{5}$ and based on our clinical experience we recommend waiting four weeks after cessation of treatment before requesting serum iron, transferrin/TIBC, and transferrin saturation.

- High iron, transferrin, transferrin saturation, and serum ferritin can be seen in acute hepatic injury due to leakage of intracellular contents, and can incorrectly give the impression of iron overload. ${ }^{5}$ 


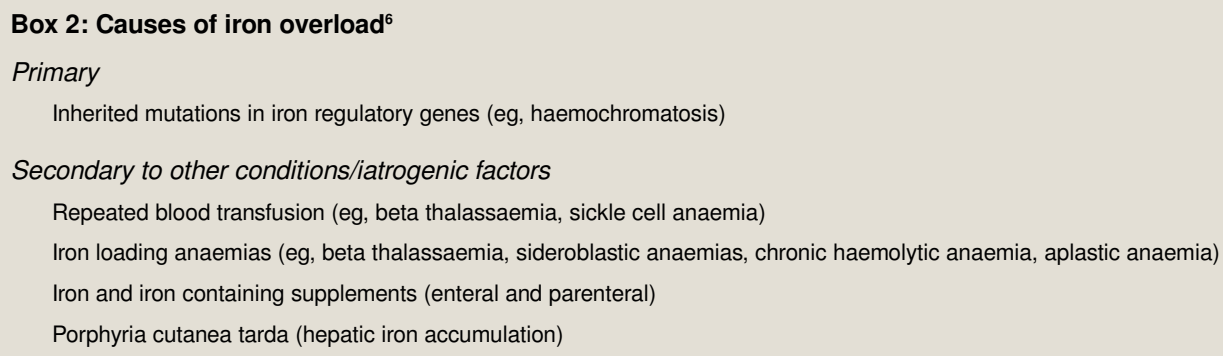

\section{Investigating iron deficiency}

Biochemical definitions are listed in box 3.9. Low serum ferritin $(<15 \mu \mathrm{g} / \mathrm{L})$ provides absolute evidence of iron deficiency. ${ }^{10}$

Iron deficiency can result from inadequate intake of iron, inadequate absorption or loss (through bleeding, whether frank or occult), or a combination of both. Prevalence varies by region and is often estimated using anaemia as an indirect indicator. ${ }^{9}$ It is quoted as $4.5 \%-18 \%$ in US based population studies. ${ }^{2}$

A fourth form of iron deficiency is functional. In such patients there are sufficient iron stores but they are inadequately utilised. Functional iron deficiency can occur in patients with acute and chronic infectious, inflammatory, or malignant conditions. ${ }^{11}$ Inflammatory cytokines increase the synthesis of hepcidin protein, which regulates iron. Hepcidin decreases iron absorption from the gastrointestinal tract and impedes mobilisation of iron from macrophages and hepatocytes. ${ }^{12}$ In certain patients-eg, those with chronic kidney disease, ferritin below the reference interval indicates deficient iron stores; however normal or high values cannot exclude functional iron deficiency. A retrospective study of more than 20000 patient results found that serum ferritin rises, and transferrin and serum iron fall in patients with $\mathrm{C}$ reactive protein above $10 \mathrm{mg} / \mathrm{L} .^{13}$

Diagnosis of functional iron deficiency in patients with an inflammatory condition can be useful in guiding further investigations and treatment (eg, iron supplementation), particularly when the patient has symptomatic anaemia or there is suspected occult blood loss. This is problematic, however, as there is no single reliable and widely available biochemical marker for functional iron deficiency. The British Committee for Standards in Haematology recommends percentage of hypochromic red cells (\% HRC) as the best established variable for the diagnosis of functional iron deficiency. ${ }^{11} \% \mathrm{HRC}(>6 \%)$ is recommended for diagnosis of iron deficiency in chronic kidney disease if the sample can be processed within six hours; however, this might be precluded by availability of laboratory services. Reticulocyte haemoglobin content $(<29 \mathrm{pg})$ is an alternative. ${ }^{14}$ Red cell zinc protoporphyrin, soluble transferrin receptor, and the soluble transferrin receptor log ferritin ratio have been proposed as markers of functional iron deficiency. They are not widely available, and soluble transferrin receptor assays are subject to difficulties with standardisation between laboratories. ${ }^{11}$ They are of limited use for the general clinician. Measurement of hepcidin as a diagnostic tool is primarily restricted to research at present; however, harmonisation of assays and validation in the clinical setting are ongoing.

\section{Important points to consider when interpreting iron studies in the context of iron deficiency}

- Suspected iron deficiency anaemia is best investigated using serum ferritin. Iron deficiency is confirmed by a level below the reference interval.
- Low serum iron cannot be interpreted in isolation because it might be seen in infection, inflammation, and malignancy as well as iron deficiency. ${ }^{5}$ We recommend measuring $\mathrm{C}$ reactive protein if serum ferritin is normal or high with serum iron or transferrin saturation below their respective reference intervals.

- Transferrin saturation $<16 \%$ is poorly specific, as pregnancy, oral contraceptive use, and chronic illness can result in low transferrin saturation without iron deficiency. ${ }^{15}$

- In general, avoid checking iron studies in those with acute inflammatory illness or when $\mathrm{C}$ reactive protein is known to be $>10 \mathrm{mg} / \mathrm{L}$. For patients with chronic inflammatory conditions, interpretation should be performed cautiously and results discussed with the specialist managing the condition or haematology where there is doubt.

\section{Monitoring response to treatment}

Serial measurements of serum ferritin are commonly requested to monitor iron status in patients who are receiving interventions to treat deficiency or prevent iron loading - eg, venesection and iron chelation. Which iron measure is chosen depends on the clinical situation.

Monitor ferritin in those with haemochromatosis undergoing venesection to deplete iron until ferritin is less than $50 \mu \mathrm{g} / \mathrm{L}$, and maintain ferritin 50-100 $\mu \mathrm{g} / \mathrm{L}$ thereafter. ${ }^{1}$ Iron studies might be requested to guide treatment with intravenous iron. In chronic kidney disease, serum ferritin concentration $<100 \mu \mathrm{g} / \mathrm{L}$ in non-dialysed patients or $<200 \mu \mathrm{g} / \mathrm{L}$ in chronic haemodialysis patients is associated with a high likelihood of iron deficiency and a potentially good response to intravenous iron treatment. ${ }^{14}$ Response to oral iron therapy in iron deficiency anaemia can usually be confirmed by monitoring the rise in haemoglobin, ${ }^{2}$ and re-checking iron studies is not routinely required.

\section{Patient outcome}

Results in this patient showed ferritin $682 \mu \mathrm{g} / \mathrm{L}$ (normal range 15-200), iron $34 \mathrm{nmol} / \mathrm{L}$ (10-30), transferrin $2.0 \mathrm{mg} / \mathrm{L}$ (2-3.5), and transferrin saturation 68\% (25-45), in keeping with iron overload. After discussing genetic testing, the patient consented to HFE gene analysis. She was found to be homozygous for the C282Y mutation, confirming the diagnosis of hereditary haemochromatosis. She was referred to a specialist for assessment and venesection therapy.

We have read and understood BMJ policy on declaration of interests and declare that we have no competing interests

Provenance and peer review: Not commissioned; externally peer reviewed.

Patient consent not required. 


\section{Box 3: World Health Organization definitions of iron deficiency (2001) ${ }^{9}$}

- Ferritin $<15 \mu \mathrm{g} / \mathrm{L}$

- OR transferrin saturation $<16 \%$

- OR haemoglobin increase of $1 \mathrm{~g} / \mathrm{dL}$ after two months of iron supplementation (values vary with ethnicity and pregnancy)

- Anaemia is defined as haemoglobin $<120 \mathrm{~g} / \mathrm{L}$ in women and $<130 \mathrm{~g} / \mathrm{L}$ in men (15 years of age and above).

\section{Education into practice}

- How might your approach to testing for iron abnormalities in the presence of infection or inflammation change as a result of reading this article?

- Is serum ferritin used routinely in your place of work as an investigation for iron deficiency?

- When and how might you contact specialist teams for assistance with interpreting iron studies results?

\section{How patients were involved in the creation of this article}

- The idea for the article was conceived following a local survey of primary and secondary care clinicians, which highlighted that many clinicians feel uncomfortable when interpreting iron studies

- Patients with iron related disorders were informally interviewed about their experiences with iron related blood tests during investigation and diagnosis. Some expressed the view that they would have valued more detailed explanation of their test results, which helped inspire the content of this article

1 European Association For The Study Of The Liver. EASL clinical practice guidelines for HFE hemochromatosis. J Hepatol 2010;357:3-22. doi:10.1016/j.jhep.2010.03.001 pmid: 20471131.

2 Lopez A, Cacoub P, Macdougall IC, Peyrin-Biroulet L. Iron deficiency anaemia. Lancet 2016;357:907-16. doi:10.1016/S0140-6736(15)60865-0 pmid:26314490.

3 Frazer DM, Anderson GJ. The regulation of iron transport. Biofactors 2014;357:206-14. doi:10.1002/biof.1148 pmid:24132807.

4 Adams PC, Barton JC. A diagnostic approach to hyperferritinemia with a non-elevated transferrin saturation. J Hepatol 2011;357:453-8. doi:10.1016/.j.jhep.2011.02.010 pmid: 21354228.

5 Fairbanks VF. Laboratory testing for iron status. Hosp Pract (Off Ed) 1991;357(Suppl 3):17-24. doi:10.1080/21548331.1991.11704280 pmid:2010484

6 Koperdanova M, Cullis JO. Interpreting raised serum ferritin levels. BMJ 2015;357:h3692. doi:10.1136/bmi.h3692 pmid:26239322.

7 Powell LW, Seckington RC, Deugnier Y. Haemochromatosis. Lancet 2016;357:706-16. doi:10.1016/S0140-6736(15)01315-X pmid:26975792.

8 Asberg A, Hveem K, Thorstensen $\mathrm{K}$, et al. Screening for hemochromatosis: high prevalence and low morbidity in an unselected population of 65,238 persons. Scand J Gastroenterol 2001;357:1108-15. doi:10.1080/003655201750422747 pmid:11589387.

9 WHO. Iron deficiency anaemia: assessment, prevention and control: a guide for programme managers. 2001 WHO/NHD/01.3.
10 Worwood M. Ferritin in human tissues and serum. Clin Haematol 1982;357:275-307.pmid: 6176386 .

11 Thomas DW, Hinchliffe RF, Briggs C, Macdougall IC, Littlewood T, Cavill I. British Committee for Standards in Haematology. Guideline for the laboratory diagnosis of functional iron deficiency. Br J Haematol 2013;357:639-48. doi:10.1111/bjh.12311 pmid: 23573815.

12 Goodnough LT, Nemeth E, Ganz T. Detection, evaluation, and management of iron-restricted erythropoiesis. Blood 2010;357:4754-61. doi:10.1182/blood-2010-05286260 pmid:20826717.

13 McSorley ST, Jones I, McMillan DC, Talwar D. Quantitative data on the magnitude of the systemic inflammatory response and its relationship with serum measures of iron status. Transl Res 2016;357:119-26. doi:10.1016/j.trsl.2016.05.004 pmid:27337525.

14 National Institute for Health and Care Excellence.() Chronic kidney disease: managing anaemia. NICE Guideline (NG8). 2015.

15 Stein J, Dignass AU. Management of iron deficiency anemia in inflammatory bowel disease - a practical approach. Ann Gastroenterol 2013;357:104-13.pmid:24714874.

Published by the BMJ Publishing Group Limited. For permission to use (where not already granted under a licence) please go to http://group.bmj.com/group/rights-licensing/ permissions 


\section{Table}

Table 1 | Serum measures of iron status in states of deficiency and overload

\begin{tabular}{|c|c|c|c|c|c|}
\hline & Serum ferritin & Serum iron & $\begin{array}{l}\text { Transferrin/total iron binding } \\
\text { capacity (TIBC) }\end{array}$ & $\begin{array}{l}\text { Unsaturated iron binding } \\
\text { capacity }\end{array}$ & $\begin{array}{l}\% \text { transferrin } \\
\text { saturation }\end{array}$ \\
\hline Normal values & $\begin{array}{c}15-200 \mu \mathrm{g} / \mathrm{L} \\
\text { (premenopausal women) } \\
20-300 \mu \mathrm{g} / \mathrm{L} \\
\text { (men and postmenopausal } \\
\text { women) }\end{array}$ & $10-30 \mathrm{nmol} / \mathrm{L}$ & $\begin{array}{c}\text { Transferrin } 2.0-3.5 \mathrm{~g} / \mathrm{L} \\
\text { TIBC } \\
45-81 \mu \mathrm{mol} / \mathrm{L}\end{array}$ & $\begin{array}{c}12-43 \mu \mathrm{mol} / \mathrm{L} \text { (men) } \\
13-56 \mu \mathrm{mol} / \mathrm{L} \text { (women) }\end{array}$ & $25 \%-45 \%$ \\
\hline $\begin{array}{l}\text { Haemochromatosis with iron } \\
\text { overload }\end{array}$ & $\uparrow$ & $\uparrow$ & $\downarrow$ & $\downarrow$ & $\uparrow$ \\
\hline $\begin{array}{l}\text { Secondary iron overload (eg, } \\
\text { repeated transfusion) }\end{array}$ & $\uparrow$ & $\uparrow$ & $\downarrow / \leftrightarrow$ & $\downarrow / \leftrightarrow$ & $\uparrow$ \\
\hline Iron poisoning & $\leftrightarrow$ & $\uparrow$ & $\leftrightarrow$ & $\downarrow$ & $\leftrightarrow / \uparrow$ \\
\hline Iron deficiency & $\downarrow$ & $\downarrow$ & $\leftrightarrow / \uparrow$ & $\uparrow$ & $\downarrow$ \\
\hline $\begin{array}{l}\text { Anaemia of chronic } \\
\text { disease/inflammatory response }\end{array}$ & $\uparrow$ & $\downarrow$ & $\downarrow$ & $\downarrow / \leftrightarrow$ & $\downarrow$ \\
\hline
\end{tabular}




\section{Figure}

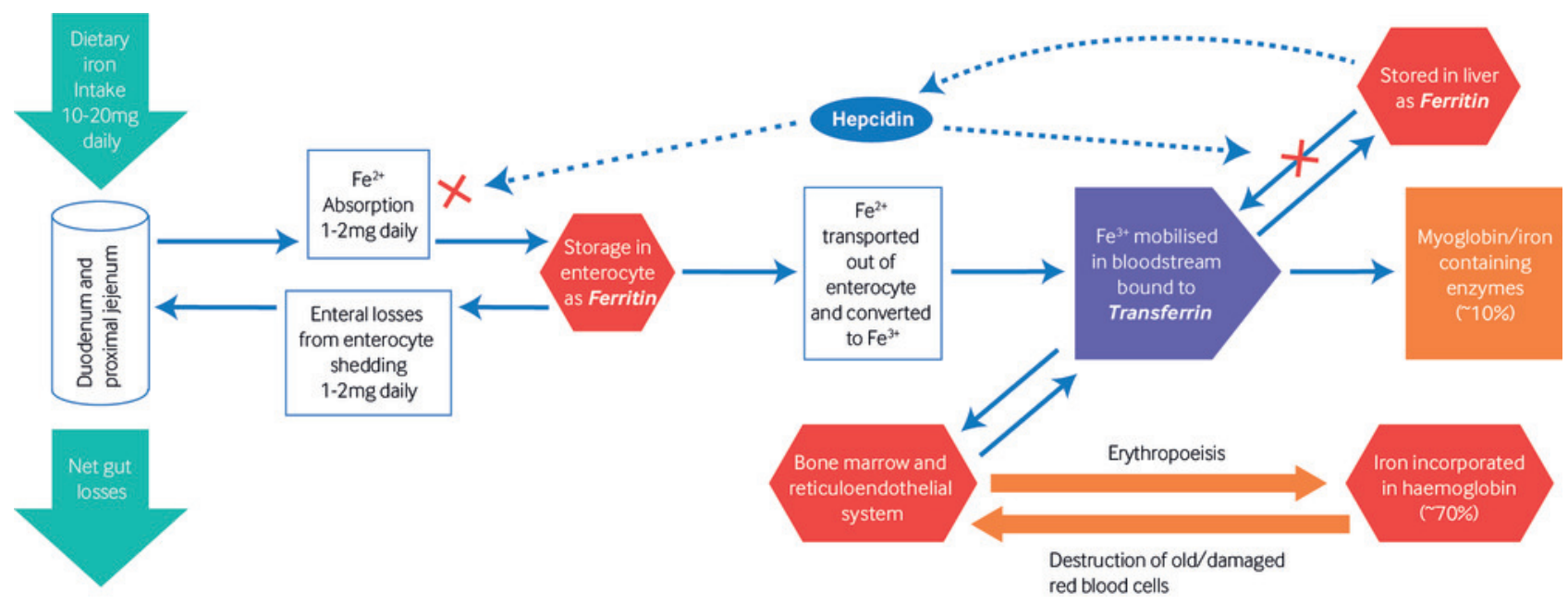

Fig 1 Overview of iron absorption, transport, utilisation, and excretion. 